\title{
Science Academies' Refresher Course in Theoretical Physics
}

\author{
January 6-20, 2015
}

at Department of Physics, Tezpur University (a Central University), Assam

Sponsored by Indian Academy of Sciences, Bangalore, Indian National Science Academy, New Delhi, The National Academy of Sciences, India, Allahabad A two week Refresher Course on Quantum mechanics (QM) and Quantum field theory (QFT) will be held in Tezpur, Assam during 6-20 January 2015. The course will cover the basics of the two fields with an emphasis on examples from topics of current interest, which can be used in teaching as examples to motivate students.

Applications are invited for the Course from teachers who are teaching undergraduate and/or postgraduate courses in physics or, if relevant, in chemistry or in mathematics. Research Scholars who are motivated to teach physics in the near future may also apply.

Resource Persons: Professors R Shankar (IMSc, Chennai), SC Phatak (CBS, Mumbai), Sumathi Rao (HRI, Allahabad), Amarjyoti Choudhury (Tezpur University); Sudpita Mukherji (IOP, Bhubaneswar), Bobby Ezhuthachan (RKM Vivekananda University, Belur Math, W.B), Poulouse Poulose (IITG, Guwahati)

Course Director: Somendra M Bhattacharjee, Course Coordinator: Ng. K. Francis

Local hospitality will be provided to all the outstation participants. Actual travel expenses by bus and/ or $3 \mathrm{AC}$ train by the shortest route will also be reimbursed.

Interested applicants must submit their application Online by clicking on this link:

http://web-japps.ias.ac.in:8080/Refreshcourse/RCTP.jsp

A printed copy of the application form signed by the applicant along with a recent detailed CV must be sent through the Head of the Institution by speed post to the Course Coordinator, Refresher Course in Theoretical Physics, Department of Physics, Tezpur University, Napam-784028, Tezpur, Assam.

For any query, please email to: $\underline{\text { rctu2015@gmail.com, }}$

Last date for receiving applications: 30 October 2014. 